\title{
Storytelling y comunicación multidireccional: una estrategia formativa para la era digital
}

\author{
Storytelling and multidirectional communication: \\ a formative strategy for the digital age
}

(ID) Andrés Hermann-Acosta

andres.hermann@ute.edu.ec

Universidad UTE (Quito, Ecuador)

https://orcid.org/0000-0001-9068-0692

DOI: https://doi.org/10.32719/26312514.2020.3.3

\section{Resumen}

El presente trabajo de investigación se enfocó en reflexionar cómo el storytelling constituye una estrategia que impulsa el paso de un modelo de comunicación unidireccional hacia uno de tipo multidireccional. Así también, en los alcances que tiene para promover la configuración de un modelo de educación abierta, flexible e interactiva. Para la obtención de los resultados de investigación, se realizó una revisión del estado del arte de los ámbitos de estudio como el storytelling, comunicación dialógica y multidireccional y la aplicación del Storytelling en el ámbito educativo. El tratamiento metodológico empleó la búsqueda de fuentes primarias y bibliográficas a partir de repositorios de alto impacto. Lo antes expuesto permitió llegar a la conclusión de que el uso del storytelling basado en consideraciones comunicacionales y pedagógicas, no artefactuales, favorece la consolidación de esquemas de comunicación y educación abiertos, dialógicos y multidireccionales.

\section{Abstract}

This research work focused on reflecting how Storytelling constitutes a strategy that drives the transition from a unidirectional communication model to a multidirectional one, as well as the scope it has to promote the configuration of an open, flexible education model. Interactive, in order to obtain the research results, a review of the state of the art in study areas such as Storytelling, dialogic and multidirectional communication and the application of Storytelling in the educational field was carried out. The methodological treatment used the search for primary and bibliographic sources from high-impact repositories. The foregoing allowed us to conclude that the use of Storytelling based on non-artefactual communicational and pedagogical considerations favors the consolidation of open, dialogic and multidirectional communication and education schemes.

\section{Palabras clave • Keywords}

Storytelling; comunicación multidireccional; narrativas transmedia; convergencia de medios. Storytelling; multidirectional communication; transmedia narratives; media convergence. 


\section{Introducción}

El storytelling se entiende como una técnica de contar historias a partir del empleo de medios electrónicos. La revisión sistemática del estado del arte indica que el storytelling tiene sus orígenes en ámbitos como la literatura, el cine y el marketing, mientras que, de manera más reciente, se está empleando en ámbitos como la comunicación y la educación, para construir experiencias dialógicas, abiertas, dinámicas y multidireccionales (Villa, Valencia y Valencia 2016).

Los relatos digitales pueden tener varias formas, ya sean imágenes fijas con narración, videos, documentales, creaciones profesionales o producciones estudiantiles. Además, se entiende como el arte de contar cuentos con una variedad de elementos digitales multimedia como imágenes, audio, video y música para presentar la información de un tema específico (Rosales-Statkus y Roig-Vila 2017, 166).

La presente investigación abordó cómo el uso del storytelling puede promover el paso de una comunicación unidireccional hacia una de tipo multidireccional y, en el caso de la educación, impulsar un modelo educativo que favorece los procesos de alfabetización digital y esquemas centrados en los profesores y los estudiantes en igualdad de condiciones. Para lograr lo antes planteado, se trabajó en tres cuerpos en el apartado de discusión teórica, que se presentan de la siguiente manera: a) storytelling, aproximaciones y dinámicas en la era digital; b) storytelling y comunicación dialógica y multidireccional; $y, c)$ storytelling, una estrategia formativa en la era digital.

Con la idea de establecer un hilo conductor a la discusión, se inició por la reflexión sobre qué se entiende por storytelling en los contextos mediados por tecnologías, sus aportes en la comunicación y la educación. Para esto se logró presentar, como una de las primeras reflexiones, que esta técnica de relatar historias de manera experiencial y vivencial debe dar el paso del logro de competencias digitales (adquisición de habilidades tecnológicas) y competencias comunicacionales (saber leer y escribir correctamente), hacia el logro de competencias narrativas (relacionado con la capacidad de seleccionar, interpretar y evaluar los datos e información).

La formación docente debe orientarse al dominio de lenguajes específicos básicos (textual, icónico, visual, gráfico y sonoro), a la adquisición de habilidades para decodificar y transferir información a variadas situaciones y contextos, y a la creación de recursos y materiales multiformato, apoyándose en diferentes lenguajes y soportes, para potenciar la capacidad expresiva y creativa mediante el uso de herramientas digitales (Del Moral, Villalustre y Neira 2016, 27).

El problema que pretende resolver esta investigación se enfocó en definir qué es el storytelling en el contexto del uso de las tecnologías digitales y cómo su empleo permite repensar los modelos de la comunicación y la educación en el marco de una cultura digital. En lo que respecta a los métodos, se abordó un enfoque de investigación descriptivo, 
basado en el uso de referencias bibliográficas obtenidas de repositorios de alto impacto (Callejo y Viedma, 2006).

\section{Storytelling, aproximaciones y dinámicas en la era digital}

La integración de las nuevas tecnologías de la información y la comunicación (NTIC), en el actual momento histórico, no solo ha generado aportes en los procesos de tecnificación y automatización de las actividades del ser humano, sino que también ha incidido en aspectos vinculados con la economía, comunicación, educación, entreteniendo y la configuración de una nueva cultura digital.

Para el teórico de la comunicación, Jean Cloutier (2010), las NTIC o tecnologías digitales constituirían las herramientas que permitan dar el paso de una comunicación unidireccional, hacia una comunicación multidireccional; este aspecto, en contraposición de la visión de la arquitectura de las tecnologías analógicas como la radio, televisión, prensa, que proponen esquemas comunicativos cerrados, en que el emisor genera un mensaje y el receptor lo recibe sin capacidad de retorno, mientras que las herramientas como los ordenadores y las tecnologías móviles permiten que los emisores y receptores se conviertan en prosumers, es decir, emisores y receptores de los datos e información (Aparici 2010b).

Lo antes expuesto permite dimensionar que la implantación de las tecnologías digitales ha traído consigo la configuración de algunas estrategias que permiten la generación de una comunicación más abierta, horizontal y dialógica, a partir del storytelling, que constituye una técnica para informar, mientras se cuentan historias a partir de medios electrónicos o soportados a través del uso de la red internet. "Storytelling (narración) es el arte del uso del lenguaje, la comunicación, la emotividad, la vocalización, la psicología del movimiento (ademanes, gesticulación y expresión) y la construcción abstracta de elementos e imágenes de una historia en particular para un público específico" (EduTrends 2017, 5).

En el marco de la preocupación de la comunicación, en torno al dar el paso de un modelo unidireccional y transmisivo hacia uno de tipo dialógico y multidireccional, el storytelling, como técnica que permite contar historias en los diferentes medios o plataformas, se mira como una estrategia para impulsar que las audiencias no solo generen un contenido emocional, sino que puedan establecer un dinamismo y sean partícipes en los procesos de construcción colectiva y colaborativa de los datos e información.

$\mathrm{Al}$ interior de las dinámicas comunicacionales, el storytelling posibilita construir una comunicación no lineal, sino hipertextual, lo que provoca un empoderamiento en el narrador y un mayor interés en la focalización de los espectadores, ya que, al momento de recibir el mensaje, no solo se estará integrando información, sino un contenido emocional, que proviene de los prosumer, los cuales están contando algo no desde una visión tecnicista, sino vivencial y experiencial. "En su forma más simple, la narración sigue siendo 
un poderoso elemento de comunicación utilizado como una estrategia para humanizar el aprendizaje, que ofrece la oportunidad de conectarse con personas que poseen gustos o caracteres similares y además permite ver el mundo desde la perspectiva de otra persona" (EduTrends 2017, 6).

El poder que tiene esta técnica es que construye un vínculo entre el emisor y las audiencias, ya que sucede que, en el cerebro del receptor, se genera un contenido emocional, aspecto que es propio del uso de las narrativas multimediales, hipertextuales, hipermediales y transmedia, ya que propenden la integración de lenguajes visuales, sonoros e interactivos (Hermann 2015).

El término storytelling es una categoría propia del entorno anglicista, pero, en contextos donde prima el castellano, se lo puede identificar como narrativa digital o relato digital. Si bien es cierto que esta técnica ya ha sido aplicada en la segunda mitad del siglo $\mathrm{XX}$, en ámbitos como la literatura, el cine y el marketing, en este último tiempo está tomando fuerza en contextos como la comunicación que quiere lograr audiencias activas y participativas, así como en la educación sobre el supuesto de configurar modelos educativos horizontales, flexibles, dinámicos y abiertos.

De esta forma, autores como Rosales-Statkus y Roig-Vila (2017) consideran que el storytelling constituye un relato que se presenta como arte para transmitir acontecimientos, a partir de imágenes, palabras y sonidos, lo que permite entender la dimensión multimodal de esta técnica, la cual favorece a la comunicación de tipo multidireccional.

El relato es interactivo, usa palabras, usa distintas acciones como la vocalización, movimientos físicos y/o gesticulaciones para presentar una historia. Todos estos elementos permiten a los alumnos utilizar sus habilidades y conocimientos, ya que siempre que se cuenta una historia, el oyente explora nuevos mundos y escenarios, al tiempo que desarrolla habilidades de pensamiento crítico para conectarlos a su propio mundo de experiencias (Rosales-Statkus y Roig-Vila 2017, 164).

La característica más importante del storytelling es su lenguaje que está basado en un contenido emocional y experiencial, aspecto que causa interés en las audiencias, ya que conecta con sus vivencias e historias personales. Además, está la interactividad propia de los medios digitales que generan dinamismo entre los emisores y receptores.

Estos nuevos esquemas de comunicación, ya identifican unas formas particulares de contar historias desde enfoques participativos, inversivos y cocreados, lo que permite romper la linealidad de la comunicación, y configurar lenguajes bifurcados, hipertextuales, amplificados y multimodales. De esta forma, con la emergencia de las tecnologías digitales, los relatos digitales, pueden ser 2.0 y 3.0, en el sentido de que las audiencias colaboran en la cocreación de los mensajes y logran hibridar la comunicación entre los entornos físicos y digitales. "Gracias a las redes sociales, las historias se pueden convertir en relatos con final abierto, con ramificaciones, hiperenlazados, con múltiples medios 
(textos, imágenes, sonidos, enlaces, etc.), participativos, exploratorios e impredecibles" (Rosales-Statkus y Roig-Vila 2017, 170).

El storytelling en la actual era digital se caracteriza por emplear medios digitales, lo que posibilita que las historias puedan ser dinámicas, interactivas y multisecuenciales. Lo que se propende en la construcción de estos lenguajes, que son representados por lenguajes multimediales o discursos audiovisuales, es que sean cortos, granulados y con una alta carga de contenido emocional.

La narración digital combina el arte de contar historias con una mezcla de medios digitales, incluyendo texto, imágenes, audio grabado, narración, música y video. Estos elementos multimedia se mezclan entre sí utilizando los programas informáticos, para contar una historia que, por lo general, gira en torno a un tema específico y con frecuencia contiene un punto de vista particular. (Robin 2016, 18)

Para autores como Del Moral, Villalustre y Neira (2016), el storytelling o los relatos digitales, posibilitan la activación de competencias digitales (manejo de la tecnología), competencias lingüísticas (promoción de la escritura y lectura) y competencias narrativas (relacionadas con el procesamiento de información). Además Robin (2016) plantea que esta técnica, en términos comunicacionales, permite organizar de mejor manera las ideas, formular mejores preguntas, organizar el pensamiento, expresar opiniones, sintetizar, contextualizare interpretar mensajes y construir discursos multimodales.

El storytelling juega un papel clave al momento de impulsar una comunicación multidireccional, ya que las audiencias se convierten en prosumer, es decir, que intercambian información, construyen significados de manera colectiva y cocreada. Así, en el caso de la educación, se estaría promoviendo el construir conocimientos de manera colaborativa, creativa a la vez que se consolidan los procesos de alfabetización digital.

La narración digital puede fomentar la creatividad, así como dar a los estudiantes una voz, ya que utilizan sus historias para compartir sus ideas y sentimientos con los demás. Un punto fuerte del proceso de narración digital es que puede ser utilizado para facilitar la escritura a través de guiones y guiones gráficos y promover la participación y la reflexión de los estudiantes. (Robin 2016, 19)

En lo que respecta al storytelling y sus aportes en los ámbitos de la comunicación y la educación, se puede decir que son casi recientes. De esta forma, en la Universidad de Texas, se pudo identificar un proyecto de investigación impulsado por el Center for Digital Storytelling (https://www.storycenter.org) que ha integrado esta técnica como una metodología de enseñanza, pero también como una estrategia que posibilita promover el desarrollo de competencias comunicativas y tecnológicas, a partir de la producción audiovisual. La metodología se basa en la creación de historias personales por parte de los estudiantes, a partir del uso de herramientas tecnológicas como los celulares. Joe Lambert (2010) considera que el storytelling promueve el logro de procesos como la alfabetiza- 
ción digital, promoción de una comunicación abierta y distribuida y la consolidación de un aprendizaje experiencial.

Nuestras mentes construyen un sentido de la memoria inmediatamente al ser parte de una experiencia o escuchar una historia. Después de una experiencia dramática, se tiene una razón particular para recitar constantemente la historia de la experiencia, que disminuye lentamente en nuestra memoria. La recuperación de una historia o experiencia dada se hace más difícil cuanto más lejos estamos en el tiempo de la historia original del evento (Lambert 2010, 1).

El storytelling o los relatos digitales potencian el acto de comunicar ideas y crear vínculos con los espectadores a partir del contenido emocional y las experiencias compartidas. Como habría referido Hermann (2015), este tipo de tecnologías digitales permiten un diálogo multimodal y multidireccional, a la vez que configuran entornos comunicacionales abiertos, flexibles y de acceso amplio a las audiencias.

Los procesos de alfabetización digital a partir del storytelling no estarán aportando solo al logro de competencias comunicacionales, entendidas como la condición de que el hablante necesita saber para comunicarse efectivamente en diferentes contextos culturales (Del Moral, Villalustre y Neira 2016), sino también al ámbito educativo, como una forma estimulante de asimilar y comprender la información que ingresa por canales visuales, sonoros y sensoriales, lo que posibilita la implantación de una educación dialógica, flexible y cocreada.

La formación docente debe orientarse al dominio de lenguajes específicos básicos (textual, icónico, visual, gráfico y sonoro), a la adquisición de habilidades para decodificar y transferir información a variadas situaciones y contextos, y a la creación de recursos y materiales multiformato, apoyándose en diferentes lenguas y soportes, para potenciar la capacidad expresiva y creativa mediante el uso de herramientas digitales. (Del Moral, Villalustre y Neira 2016, 27).

\section{Storytelling y comunicación dialógica y multidireccional}

Se ha definido al storytelling como una técnica que permite contar historias a partir de medios digitales en el contexto de la sociedad red, donde sus formas de comunicación poseen la característica de multidireccional, ya que sus narrativas son multimediales, hipertextuales, hipermediales y transmedia, lo que posibilita la exposición de lenguajes bifurcados, expandidos, abiertos y multimodales (Hermann 2015).

Pero, para comprender lo que implica la articulación del storytelling en los procesos de comunicación dialógica y multidireccional, es importante reflexionar lo que son los relatos audiovisuales, que, en una sociedad mediada por las tecnologías digitales, se entretejen en una cultura de la pantalla, uso de lenguajes visuales y sonoros. "Las imágenes pueden contener discursos en la medida en que permiten configurar ideas acerca de la 
realidad y las imágenes en movimiento que se ven en la pantalla conforman un tipo particular de discurso que representa algunas de las maneras de vivir, pensar, sentir, el mundo en determinado marco histórico y cultural" (Ordóñez 2013, 49).

En una sociedad mediática, el uso de los discursos audiovisuales está combinado con los discursos sonoros (la música). De esta manera, el storytelling configura las narrativas multimediales que permiten la generación de sentimientos y afectos, lo que brinda uno de los mayores atributos a esta técnica, como es el contenido emocional, como condición que permite provocar interés en las audiencias. "La música es el elemento que sostiene la identificación, así como la forma narrativa, en tanto permite la continuidad emocional en la percepción del plano y provoca la rememoración de la experiencia del espectador" (Ordóñez 2013, 7).

Todos los atributos antes expuestos permiten que el storytelling basado en la narrativa audiovisual favorezca que las dinámicas entre los emisores y receptores se replanteen, es decir, los emisores ya no son solo los responsables de direccionar los mensajes y los receptores aquellos actores que receptan la información de manera estática y sin retorno, sino que se convierten en emirec (emisores y receptores) o prosumer (consumidores y productores), logrando así la iniciativa de proponer el paso de una comunicación transmisiva, tecnocrática y funcionalista, hacia una comunicación abierta, dialógica y multidireccional.

En cuanto a los contenidos de la narrativa audiovisual, hablar de identificación es tratar el tema del espectador. En el cine, la interpretación que hace el espectador es indisoluble de la narrativa audiovisual. Lo que se ve y se escucha reverbera emocionalmente en el espectador gracias a la compresión del género y su inclusión en el campo cultural apropiado para esa sensibilización. (Ordóñez 2013, 27).

Pero, para entender qué implica potenciar la comunicación con técnicas como el storyelling, es importante destacar cuál es el sentido de la comunicación en un contexto mediado por las tecnologías digitales como internet. Para Aparici (2010a), las tecnologías analógicas como la radio, prensa, televisión, proponían la generación de modelos de comunicación funcionalistas, sustentados en la idea de que el emisor transmite mensajes y el receptor los toma y no puede realizar un acto de retroalimentación.

Con la eclosión de las tecnologías digitales, los ordenadores, telefonía móvil y el internet, las comunicaciones se replantean, ya no se basan en ejercicios aislados, individuales y unidireccionales, sino que las audiencias, en el marco de una inteligencia colectiva (Lévy 2009), logran movilizarse en el ciberespacio para construir discursos colaborativos y conectados, ya que cada persona puede llegar a ser un medio. "Se establece una relación de igual a igual entre todos los participantes del proceso y donde no existen papeles asignados para quienes participan de la comunicación: los emisores son receptores y los receptores son emisores" (Aparici 2010a, 27). 
Esto quiere decir, que las tecnologías digitales y el empleo del storytelling desde una visión multidireccional estaría dando paso de receptores pasivos a emisores productores de mensajes, lo que marca de manera muy clara lo que Aparici (2010a), refiere con respecto al salto de un modelo de comunicación centrado en la emisión, hacia un modelo negociado, en donde las personas construyen y negocian sus significados de manera horizontal.

A partir de este nuevo siglo, los individuos forman redes, se organizan, articulan movimientos y acciones desde el ciberespacio a los espacios reales y dentro del propio ciberespacio. Los individuos articulan pensamientos colectivos, construyen conocimientos y cada uno es potador de su propio medio de comunicación o de su escuela o universidad a través de la telefonía. (Aparici 2010a, 34)

Lo idea antes expuesta, da argumento para entender que, con la emergencia de las tecnologías digitales como la telefonía móvil, el esquema de comunicación se ha replanteado hacia una visión ubicua o permanente y que en el caso del Storytelling, permite la interacción de diálogos con las audiencias y el mantener discursos y acciones de carácter emocional y sensorial. De esta forma, se está construyendo el verdadero sentido de comunicación, no como acción de informar o direccionar un mensaje de forma instrumental y unidireccional, sino como plantea Aparici (2010a), como una forma de diálogo compartido, la relación que pone a dos o más personas en un proceso de transformación continua con interacción.

La comunicación debe entenderse desde la relación entre iguales, la participación activa y reflexiva de las audiencias y su colaboración mutua. Para esto se debe aprovechar del aparataje de la web 2.0, que plantea un esquema de comunicación abierta, flexible y multidireccional, en especial apoyada en herramientas como las redes sociales, wikis, blogs, LMS, CMS y el storytelling que se puede disponer en todas las plataformas tecnológicas y nueva ecología de medios (Jenkins 2008).

La web 2.0 ha permitido que cada ciudadano pueda actuar como un medio de comunicación. Pero, la mayoría de estos medios emirec que crearon sus propios blogs o que participan en redes sociales como Facebook, Tuenti o MySpace difunden y utilizan los recursos para exhibirse, para mostrarse y conocer a otros cibernautas. La gente se conoce y se muestra a través de la web, sobre todo para hablar de ella misma. (Aparici 2010a, 30)

Si bien es cierto que, en la idea anterior, se hace referencia a plataformas que tuvieron su impacto años atrás, en los fenómenos de la comunicación en la actual era digital sucede lo que se denomina el desarrollo de la convergencia de medios, que propone la integración de los viejos medios con los nuevos. De esta forma, se potencian sus usos y funcionalidades. En el caso de la radio, no ha desaparecido, sino que con el empleo de la red internet transmutó hacia el podcast y la radio en línea. Lo mismo pasó con la televisión 
analógica y su migración a lo que se denomina televisión por catálogo, como es el caso de la empresa Netflix.

Para Jenkins (2008), la convergencia tiene una relación con el flujo de contenidos en diferentes plataformas mediáticas, en las cuales, usando la dinámica de la web 2.0, las industrias cooperan e interactúan con las audiencias. El caso del storytelling es claro. En las décadas de los 80 y 90 del siglo pasado, las narrativas multimediales se presentaban a partir de lenguajes audiovisuales, comúnmente con los videos. Hoy, cuando prima una cultura de la convergencia de medios, esos videos han sido empleados para establecer puentes de comunicación y se muestran en diferentes canales mediáticos de manera granular, flexible, interactiva y con contenido emocional.

En palabras de Jenkins (2008), la comunicación en el contexto de la cultura de la convergencia de medios y las narrativas transmedia promueve un diálogo más abierto, multidireccional en situación de igualdad, lo que a su vez promueve el desarrollo de la articulación de diferentes canales tecnológicos, la cultura participativa y la potenciación de la inteligencia colectiva. "La era de la convergencia mediática hace posible los modos de recepción comunal, más que individualista. No todos los consumidores mediáticos interaccionan todavía en el seno de una comunidad virtual; los hay que simplemente comentan lo que ven con sus amigos, familiares y compañeros de trabajo" (Jenkins 2008, 36).

Estas nuevas plataformas hacen posible una mayor circulación de contenidos, presentan los mensajes en diferentes ecosistemas, a la vez que enriquece la información, ya que los emirec o prosumers alimentan y potencian los discursos y significados. A lo antes expuesto se lo conoce como cocreacón y producción de comunicaciones a partir de las experiencias de los individuos. Así, si tomamos el caso de la industria cultural, los programas televisivos como los reality shows, se puede ver que quienes enriquecen sus contenidos a partir de las colaboraciones son las comunidades de usuarios o fans, aspecto que también se está utilizando en ámbitos como la economía, educación, movilización política.

Pero de la mano de la cultura de la convergencia está el uso de las narrativas transmedia que, en este caso, plantean el flujo de contenidos en diferentes canales, aspecto que está provocando un quiebre en los modelos de la comunicación funcionalistas y unidireccionales. Si bien el término de narrativas transmedia fue introducido por Henry Jenkins, para referir el flujo de mensajes en diversas plataformas, es Carlos Scolari quien logra imbricar narrativas con el storytelling en ámbitos como la educación y el entretenimiento en el caso de los videojuegos. "Las narrativas transmedia son una particular forma narrativa que se expande a través de diferentes sistemas de significación (verbal, icónico, audiovisual, interactivo, etc.) y medios (cine, cómic, televisión, etc.)" (Scolari 2013, 24). 


\section{Storytelling, una estrategia formativa en la era digital}

Para autores como Daniel Prieto Castillo, no se puede entender la comunicación sin la educación y la educación sin la comunicación, ya que no se logra educar sin transferir información y conocimientos y no se puede comunicar a partir del acto responsable de formar a las audiencias (Aparici, 2010b).

El aporte que trae este ensayo, no solo se reduce a reflexionar como la eclosión de las tecnologías digitales han permitido dar el paso de un esquema comunicacional tecnocrático, transmisivo y unidireccional, hacia un modelo comunicacional dialógico, dinámico y multidireccional, sino como estrategias como el Storytelling está permitiendo aterrizar en la práctica todos estos principios, a partir de la configuración de un modelo educativo centrado en las audiencias, que en este caso, son los estudiantes.

El storytelling aporta en aspectos como facilitar el recuerdo, acceso sencillo a la memorización, vinculación de las emociones, adopción de nuevos puntos de vista, promoción del empleo de las TIC, desarrollo de competencias comunicativas, lingüísticas, narrativas y el desarrollo del pensamiento creativo, replantear el rol de los actores educativos. Así, el profesor, bajo este esquema, ya no es el único experto, portador del conocimiento y de la verdad y el estudiante un receptor pasivo de la información, sino que ambos se convierten en corresponsables en la construcción de los motivos educativos.

En la práctica docente, el storytelling facilita la función didáctica porque apoya al estudiante a mejorar el nivel de comprensión y discernimiento a través de la identificación con los personajes de las historias, los temas, las situaciones, la información y las exposiciones. Adicionalmente, el uso de la oralidad y las herramientas tecnológicas producen un ambiente que atrapa la atención del estudiante. (EduTrends 2017, 10)

$\mathrm{Al}$ igual que en la comunicación dialógica, donde las audiencias son el centro del proceso, el storytelling en la educación, el profesor se convierte en storyteller o relator de historias y los estudiantes en responsables y productores audiovisuales del conocimiento, aspecto que está contribuyendo al logro de una alfabetización digital y cognitiva, ya que los actores educativos están en permanente uso e interacción con herramientas tecnológicas y contenidos científicos.

El empleo del storytelling promueve, como dice Aparici (2010b), los procesos de participación, autogestión, comunicación dialógica y la concepción de la comunicación como una acción de reciprocidad, participación y colaboración. Para López (2014), desde siempre existieron relatos, siempre hubo la necesidad de contar y narrar ideas. Esto quiere decir que los relatos han estado presentes en la actividad formativa del ser humano, desde tiempos ancestrales. Es por esta razón que, con el boom de las tecnologías digitales, estos relatos o storytelling pasan a ser trabajados y presentados a partir del uso de los medios electrónicos, sobre la base de la idea primigenia, convencer, entretener, intrigar, explicar, impresionar, teorizar y crear vínculos entre el que educa y el educando (López 2014). 
Con las transposiciones a las que habilitan las tecnologías digitales surgen nuevas formas de producir y analizar los relatos. Los avances tecnológicos han ido modificando las diferentes formas de narrativa, comunicación y representación, pasando de la unidireccionalidad y el lenguaje único a la no linealidad, a la convergencia y a la participación e interactividad. (López 2014, 28)

Como se expuso en apartados anteriores, el desarrollo tecnológico y la evolución de la web 2.0 (autogestión y colaboración de las audiencias), la web 3.0 (articulación de la realidad física con la virtual) y la web 4.0 (automatización de procesos de la inteligencia colectiva hacia la inteligencia artificial), la educación está haciendo uso de estas bondades, para lograr aspectos como un proceso formativo interactivo, dinámico, flexible, abierto, multidireccional y sensorial. Sin duda, este aspecto permitirá hacer un quiebre a los modelos tradicionales sustentados en el profesor como único experto. La comunicación y la educación en un espacio 2.0 y 3.0 debe estar fundamentada en el diálogo, la participación y la construcción del conocimiento de manera colectiva y conectada.

Los principios pedagógicos y comunicativos de la educación 2.0 basados en la participación, autogestión y la comunicación dialógica han sobrevivido a los cambios tecnológicos que hemos experimentado en los últimos años. Las tecnologías digitales pueden servir para ofrecer más de lo mismo, es decir repetir el uso de viejas concepciones pedagógicas envueltas en un barniz de modernidad digital. Se hace imprescindible hablar de otro modelo de comunicación que supere los límites instaurados por los paradigmas funcionalistas. Las predicciones que se hicieron en sus orígenes ahora pueden ser realidad y cada persona puede ser y actuar como un medio de comunicación a través de blogs, wiks o videos de YouTube. (Aparici 2011, 9)

Ahora, con el paso de la web 2.0 a la web 3.0 y web 4.0, estrategias como el storytelling en educación cada vez presentan menos la información y contenidos en los ordenadores, debido a la emergencia de las tecnologías móviles, que se conocen como mobile-learning, que permiten la implantación de una comunicación y un proceso formativo ubicuo y permanente. Esto quiere decir que los esfuerzos en torno a las nuevas alfabetizaciones digitales se tendrán que enfocar en el uso de estos nuevos medios, los cuales logran competencias tecnológicas, lingüísticas de contenido científico y que replantean la territorialidad de la escuela y los nuevos entornos digitales de inmersión.

La gran ventaja del uso de los dispositivos móviles es que, a pesar de las brechas digitales que existen en algunos países, cada vez su campo de penetración va en acenso. Además, esta estrategia permite contribuir a las limitaciones de infraestructura de las instituciones educativas. Herramientas como los teléfonos inteligentes posibilitan el trabajo de manera offline o sin conexión a la red internet. "La narrativa digital y los dispositivos móviles, que son elementos que se encuentran al alcance del profesorado y del alumnado y que pueden convertirse en poderosos aliados tanto dentro como fuera del aula" (Socas y González 2013, 505). 
El storytelling en los diferentes ecosistemas o nueva ecología de medios no solo está contribuyendo al logro de las más recientes alfabetizaciones digitales, conversión de un modelo comunicacional unidireccional hacia uno de tipo multidireccional, sino que, en el campo de la educación en la era digital, está contribuyendo a aspectos como la promoción de un pensamiento organizado, desarrollo de la investigación, anclaje entre la experiencia y conocimientos previos con los aprendizajes más recientes.

Los maestros que utilizan la narrativa digital en sus clases creían que sus estudiantes aumentaron sus habilidades técnicas, de investigación, presentación, organización y escritura. Los maestros también informaron que habían pensado que el proceso de la narrativa digital tuvo efectos positivos sobre la motivación de los estudiantes y de compromiso de los niveles, capacidad de organización y la escritura. (Robin y McNeil 2012, 38)

De esta forma, en una sociedad mediada por tecnologías digitales, el aprovechamiento de medios de comunicación, organizaciones, colectivos y sector de la educación no solo se tendrá que reducir a los procesos de alfabetización digital, sino que deberá permitir un mayor aprovechamiento de estrategias como el storytelling que, en el caso de la comunicación, puede generar un mejor direccionamiento de los mensajes de manera expandida y con contenido emocional, así como en la educación, dar el paso de un modelo formativo plano, lineal y unidireccional, hacia uno que permita generar empatías con las audiencias y establecer condiciones para favorecer un mayor acceso y democratización al conocimiento.

\section{Conclusiones}

Las tecnologías analógicas como la radio, televisión y prensa, por su esquema y funcionamiento, establecen esquemas de comunicación unidireccionales, mientras que las tecnologías digitales, como los ordenadores y la tecnología móvil, incorporan un esquema de comunicación dialógico y multidireccional.

El storytelling es una técnica que permite contar historias a partir de medios electrónicos, lo que posibilita el empleo de una comunicación multidireccional y un modelo educativo, abierto, flexible, dinámico, que se basa en el aprendizaje vivencial, experiencial y de contenido emocional. Los relatos digitales, que son otra forma de referir a la categoría anglicista del storytelling, permiten, tanto en la comunicación como en la educación, transmitir ideas mientras se generan vínculos con los espectadores, las audiencias, a la vez que se construye mensajes de manera colectiva y conectada.

La emergencia de la cultura de la convergencia de medios ha permitido la inclusión de los viejos con los nuevos medios, donde el storytelling ya no solo se presenta como narrativas multimediales en canales de videos, sino que hace uso de la nueva ecología de medios como blogs, wikis, LMS, CMS y redes sociales, permitiendo que el mensaje se expanda y llegue a más audiencias. 
Las tendencias en la comunicación y la educación en la actual era digital, indican que en el paso de la web 2.0, a la web 3.0 y la web 4.0, los relatos, contenidos e información ya no se presentan solo en los ordenadores, sino en tecnologías móviles. Así también logra hibridar la realidad física con la realidad virtual que está dando el paso de una inteligencia colectiva hacia una inteligencia artificial, que favorece la implantación de esquemas de la comunicación, ubicuos, permanentes y cocreativos.

\section{Referencias}

Aparici, Roberto, coord. 2010a. Conectados en el ciberespacio. Madrid: UNED.

Aparici, Roberto. 2010b. Educomunicación: Más allá del 2.0. Barcelona: Gedisa. 2011. “Principios pedagógicos y comunicacionales de la educación 2.0”. La educ@ción, 145. http://www.educoas.org/portal/La_Educacion_Digital/laeducacion_145/articles/Roberto_Aparici. pdf

Callejo, Javier y Antonio Viedma. 2006. Proyectos y estrategias de investigación social: La perspectiva de la intervención. Madrid: McGraw-Hill Interamericana.

Cloutier, Jean. 2010. "Historia de la comunicación”. En Conectados en el ciberespacio, coordinado por Roberto Aparici, 45-50. Madrid: UNED.

Del Moral, María Esther, Lourdes Villalustre y María del Rosario Neira. 2016. "Relatos digitales: Activando las competencias comunicativa, narrativa y digital en la formación inicial del profesorado". Ocnos 15 (1): 22-41.

EduTrends. 2017. "Introducción”. EduTrends (febrero): 5-6. https://observatorio.itesm.mx/ edutrends-storytelling/

Hermann, Andrés. 2015. "Narrativas digitales como didácticas y estrategias de aprendizaje en los procesos de asimilación y retención del conocimiento". Sophía 1(19): 253-70.

Jenkins, Henry. 2008. Convergence culture: La cultura de la convergencia de medios de comunicación. Barcelona: Paidós.

Lambert, Joe. 2010. Digital Storytelling: Capturing Lives, Creating Community. Berkeley: Digital Diner Press.

Lévy, Pierre. 2009. Inteligencia colectiva por una antropología del ciberespacio. Washington:

Organización Panamericana de la Salud (OPS).

López, Susana. 2014. "Estrategias de enseñanza: Hacia la narrativa digital transmedia en el aula virtual”. Tesis de maestría, Universidad Nacional de Educación a Distancia. 
Ordóñez, Gonzalo. 2013. La narrativa del amor y la intimidad en una serie de televisión (Primera). Quito: UASB-E/Corporación Editora Nacional (CEN).

Robin, Bernard. 2016. “The power of digital storytelling to support teaching and learning”. Digital Education Review 0 (30): 17-29.

Robin, Bernard y Sara McNeil. 2012. "What educators should know about teaching digital storytelling". Digital Education Review (22): 37-51. https://eric.ed.gov/?id=EJ996781.

Rosales-Statkus, Saulius y Rosabel Roig-Vila. 2017. "El relato digital (digital storytelling) como elemento narrativo en el ámbito educativo”. Notandum (44): 163-74.

Scolari, Carlos. 2013. Narrativas transmedia: Cuando todos los medios cuentan. Vizcaya: Deusto.

Socas, Víctor y Carina González. 2013. "Usos educativos de la narrativa digital: una experiencia de m-learning para la educación emocional”. Teoría de la Educación. Educación y Cultura en la Sociedad de la Información 14 (2): 490-507.

Villa, Eliana, Jackeline Valencia y Alejandro Valencia. 2016. "El papel de las narrativas digitales como nueva estrategia educativa: Resultados desde un análisis bibliométrico”. Kepes 13 (13), 197-231 